\title{
Submucosal tunneling endoscopic resection (STER) with full-thickness muscle excision for a recurrent para-aortic esophageal leiomyoma after surgery
}

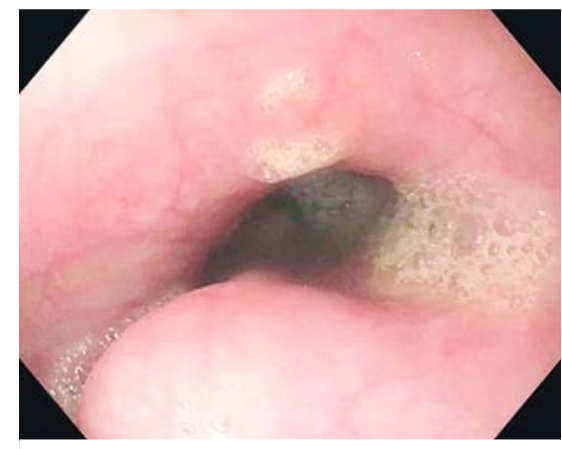

- Fig. 1 Endoscopic view showing a recurrent leiomyoma in the mid-esophagus.

We report the case of a 49-year-old woman with a recurrent esophageal leiomyoma following two surgical resections. The surgical procedures had been performed 23 and 21 years previously. Follow-up showed lesion recurrence in the mid esophagus ( $\triangleright$ Fig. 1 and $\triangleright$ Fig. 2 ).

Submucosal endoscopic tunneling resection (STER) was preferred to surgery because of the previous interventions. A single shot of $2 \mathrm{~g}$ ceftriaxone was administered intravenously prior to the procedure. Submucosal injection, mucosal incision, and tunnel creation was started $5 \mathrm{~cm}$ above the lesion. Enucleation was performed using a DualKnife J (Olympus, Tokyo, Japan). The lesion was close to the aorta, so the final dissection was carried out by synchronizing with aortic movements. Full-thickness muscle resection was required to achieve en bloc resection being careful to preserve the esophageal adventitia ( $\vee$ Video 1 ). The leiomyoma was grasped with a $30-\mathrm{mm}$ snare and was easily removed ( $\mathbf{F i g . 3}$ ). Six standard clips (QuickClip Pro; Olympus) were deployed to close the mucosal incision.

A computed tomography (CT) scan with swallow study was performed on postoperative day 1 ; oral diet was restarted on day 2. Histological examination did not show any malignancy.

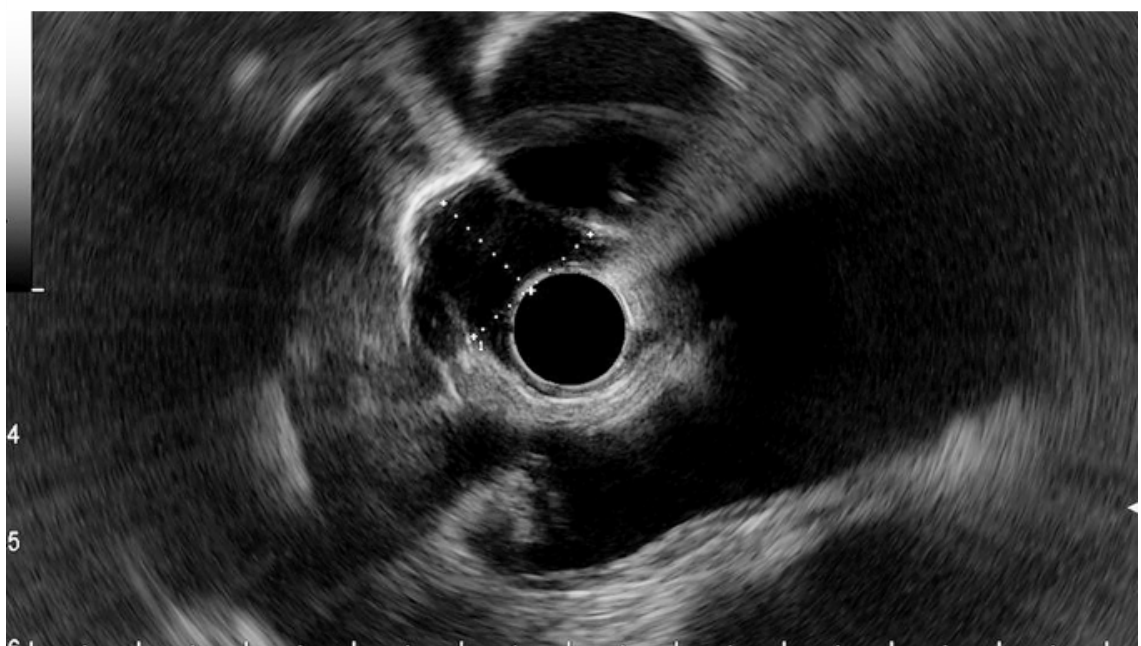

- Fig. 2 Endoscopic ultrasound (EUS) showing a huge para-aortic leiomyoma developing from the muscularis propria layer.
Tumors originating from the muscularis propria require surgery in most cases [1]. STER is a novel approach for the treatment of subepithelial tumors of the gastrointestinal tract. The risk of perforation may reach up to $15 \%$ [2]. If the tumor develops from the muscularis propria, preservation of the serosal layer is difficult; circumferential incision of the serosa is therefore often required to complete en bloc resection [3]. Even though a large muscular defect exists, mediastinitis does not occur if the mucosal continuity is maintained [4].

Recurrent esophageal leiomyoma has been anecdotally reported and is usually related to incomplete resection or enlargement of a previously undetected nodule [5]. Here, we report the first STER treatment for recurrent esophageal

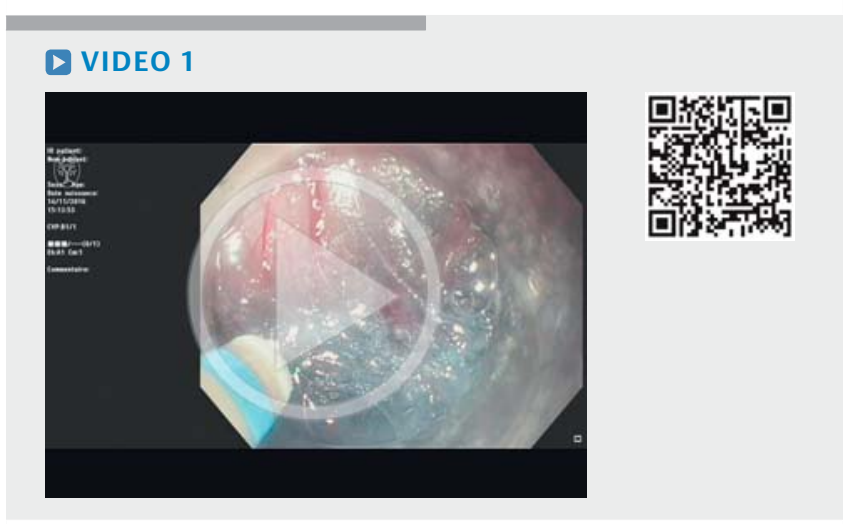

- Video 1: Peroral endoscopic tunneling dissection of a huge recurrent para-aortic esophageal leiomyoma. Muscularis propria dissection and full-thickness resection was necessary to mobilize the lesion with preservation of the esophageal adventitia. 


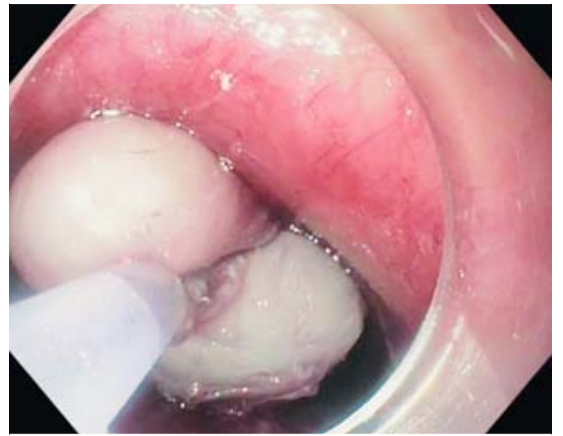

- Fig. 3 Endoscopic view showing the $15 \times 30-\mathrm{mm}$ leiomyoma being grasped by a $30-\mathrm{mm}$ snare.

leiomyoma with full-thickness muscle resection, which was required because of involvement of the deep muscularis propria and fibrosis deriving from previous surgery.

Endoscopy_UCTN_Code_TTT_1AO_2AG

\section{Competing interests}

None
Gianfranco Donatelli ${ }^{1}$, David Fuks ${ }^{2}$, Guillaume Pourcher ${ }^{2}$, Isabelle Dumontier ${ }^{1}$, Fabrizio Cereatti ${ }^{1}$, Thierry Perniceni ${ }^{2}$, Brice Gayet ${ }^{2}$

1 Unité d'Endoscopie Interventionnelle, Ramsay Générale de Santé, Hôpital Privé des Peupliers, Paris, France

2 Department of Digestive Surgery, Institut Mutualiste Monsouris, Univeristé Paris Descartes, Paris, France

\section{Corresponding author}

\section{Gianfranco Donatelli, MD}

Unité d'Endoscopie Interventionnelle, Ramsay Générale de Santé, Hôpital Privé des Peupliers, 8 Place de l'Abbé G. Hénocque, 75013 Paris, France

Fax: + 33-1-44165615

donatelligianfranco@gmail.com
References

[1] Eleftheriadis $\mathrm{N}$, Inoue $\mathrm{H}$, Ikeda $\mathrm{H}$ et al. Submucosal tunnel endoscopy: Peroral endoscopic myotomy and peroral endoscopic tumor resection. World J Gastrointest Endosc 2016; 8: 86-103

[2] Chiu PW, Inoue H, Rösch T. From Poem to Poet: Applications and perspectives for submucosal tunnel endoscopy. Endoscopy 2016; 48: $1134-1142$

[3] Xu MD, Cai MY, Zhou PH et al. Submucosal tunneling endoscopic resection: a new technique for treating upper $\mathrm{Gl}$ submucosal tumors originating from the muscularis propria layer (with videos). Gastrointest Endosc 2012; 75: 195 - 199

[4] Inoue H, Ikeda H, Hosoya T et al. Submucosal endoscopic tumor resection for subepithelial tumors in the esophagus and cardia. Endoscopy 2012; 44: 225-230

[5] Standerfer RJ, Paneth M. Recurrent leiomyoma of the oesophagus. Thorax 1982; 37: $478-479$

\section{Bibliography}

DOI http://dx.doi.org/10.1055/s-0043-100212 Endoscopy 2017; 49: E86-E87

(c) Georg Thieme Verlag KC Stuttgart · New York ISSN 0013-726X 